\title{
Los instrumentos de derechos humanos como garantes del acceso a la justicia
}

\section{Human rights instruments as guarantees of access to justice}

\author{
José Antonio Michilini* \\ http://dx.doi.org/10.21503/lex.v11i12.19
}

* Doctorando en Derecho Penal, Director del Instituto de Investigaciones de Derechos y Garantías Constitucionales de la Universidad Nacional de Lomas de Zamora. Profesor de Derechos Humanos y Procesal Penal de la Universidad Nacional de Lomas de Zamora. Director del Instituto de Investigaciones de dicha Universidad. Profesor del Collége Universitaire Henry Dunant, Ginebra, Suiza. Docente en los cursos de verano de la Universidad de La Rioja, España.
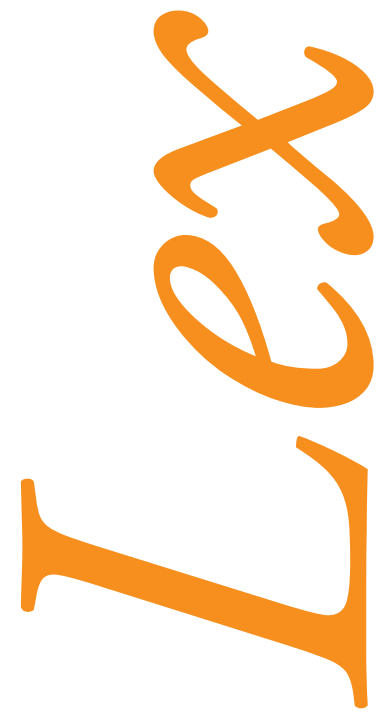


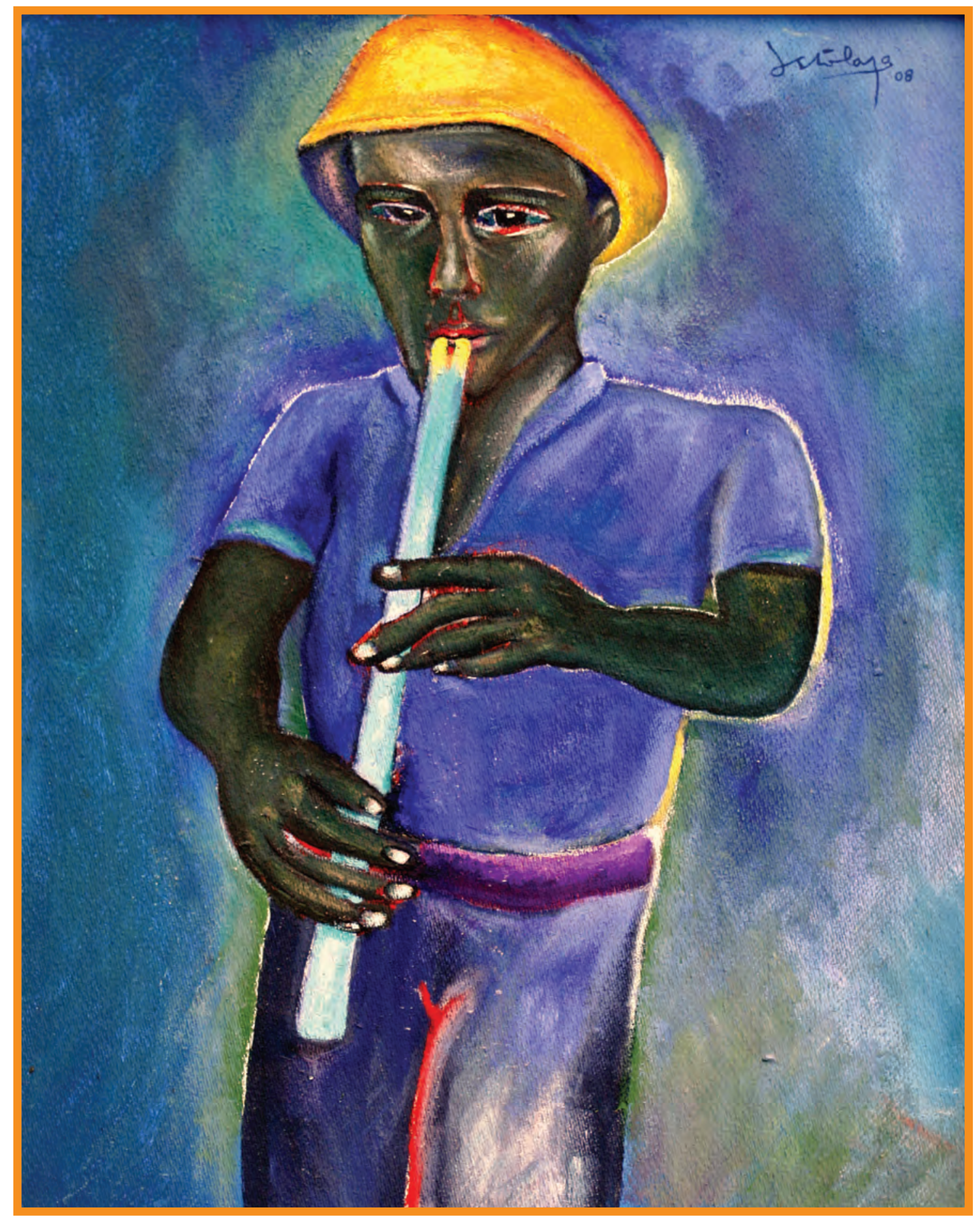

Quenista. 


\section{RESUMEN}

El presente artículo fue elaborado con la idea de formar una aproximación a la nueva concepción sobre la interpretación de los tratados y las normas de Derecho Internacional. La progresividad de los derechos humanos nos lleva a analizar de una forma diferente la incidencia de estas en el Derecho Interno, teniendo en cuenta principalmente que la mayoría de los países de América Latina y Argentina han sido signatarios de tales acuerdos.

De manera somera, he colocado sobre la mesa los principales grupos de personas sobre las que pesa una mayor dificultad de acceso a la jurisdicción, haciendo extensivo esto a la compleja normativa española.

Palabras clave: Derecho Internacional, derechos humanos, justicia penal, acceso a la justicia.

\section{ABSTRACT}

This article was elaborated with the idea of forming an approach to the new conception on the agreement interpretation and International Law Rules. The human rights progression leads to analyze in a different way the incidence of these in the Internal Right having in mind mainly that most of the countries of Latin America and Argentina have been signatories of such agreement.

In summary, I have placed on the table the main groups of people on who carry weight a biggest difficulty of access to the jurisdiction, making extensive this to the complex Spanish normative.

Key words: International Law, human rights, criminal justice, access to the justice. 



\section{INTRODUCCIÓN}

Durante muchos años, el Derecho Interno ha sido la única fuente que servía para que la magistratura emitiera sus fallos, pero esta tendencia se ha ido revirtiendo, y los máximos tribunales nacionales siguen las pautas de los órganos regionales de derechos humanos.

Desde el plano universal, se fueron generando sistemas de control de los tratados que denotan una mayor preocupación por la problemática del cumplimiento. El Pacto de Derechos Civiles y Políticos, mediante su órgano de aplicación, el Comité de Derechos Humanos, ha postulado en el 2007 la Observación General Nro. 32, generando nuevos estándares de actuación para la Justicia.

\section{ACCESO A LA JURISDICCION ${ }^{1}$}

El acceso a la justicia es un derecho fundamental, bajo la garantía de la igualdad de trato ante la ley y la no discriminación, que posibilita a todas las personas, incluyendo aquellas pertenecientes a los sectores más vulnerables, el acceso al conocimiento, ejercicio y defensa de sus derechos y obligaciones, mediante servicios cercanos.

Se lo define como "el derecho a reclamar, por medio de los mecanismos institucionales existentes en la comunidad, la protección de un derecho legalmente reconocido". ${ }^{2}$ Es dable señalar que la Constitución Nacional de la República Argentina consagra claramente el derecho de toda persona a acceder a la justicia frente a cualquier situación que estime vulnere sus derechos, tanto sea por parte de particulares como del propio Estado. ${ }^{3}$ Dicha concepción fue anticipada jurisprudencialmente a partir del conocido fallo de la CSJN "Edmekjian c/ Sofovich", donde se reconoció la supremacía de los Tratados Internacionales frente a las leyes

\footnotetext{
Extractos del presente artículo han sido publicados en el Anuario de la Universidad Nacional de Lomas de Zamora, en un escrito de mi autoría.

2 Natalia Gherardi. "Notas sobre acceso a la Justicia del Equipo Latinoamericano de Justicia y Género". 2010. En: www. ela.org.ar. Consultado el 29/02/2013.

3 Arts. 14, 17, 18, 43 y ccdtes. de la Constitución de la Nación Argentina, reformada en 1994.
} 
locales, para luego consagrarse normativamente en forma definitiva con la posterior reforma constitucional de 1994, que asignó jerarquía constitucional a los tratados internacionales de DDHH. ${ }^{4}$

En tal sentido, la última reforma constitucional no solo amplió los derechos y garantías de los habitantes de la Nación sino que también consagró constitucionalmente mecanismos judiciales para la protección de tales derechos. ${ }^{5}$ Sin duda, la reforma constitucional trajo aparejada la ampliación del conjunto de derechos sociales que pueden ser reclamados a través de procesos judiciales. Así lo han entendido y manifestado nuestros constituyentes nacionales al reformar la $\mathrm{CN}$ en 1994, y así lo han reafirmado los constituyentes de la provincia de Buenos Aires al realizar la última reforma de la Carta Magna Provincial en 1994 reafirmando los derechos y garantías consagrados en la $\mathrm{CN},{ }^{6}$ pero a la vez estableciendo artículos concretos y específicos en la referida Carta Magna provincial. ${ }^{7}$ Paralelamente a estos progresos, se vivió en la República Argentina una de las crisis económicas más profundas. Ello derivó en la ampliación del marco normativo, con el consecuente reconocimiento de derechos y un incremento de los mecanismos de acceso a la justicia, al mismo tiempo que se deterioró la calidad de vida y las condiciones económico-sociales. Así por ejemplo, aumentó la tasa de desempleo, el porcentaje de población por debajo de la línea de pobreza, la exclusión social y, junto con ello, el deterioro de los recursos del Poder Judicial y la falta de legitimación del mismo ante la incapacidad generalizada para dar respuesta a los nuevos reclamos sociales.

El principio del acceso a la jurisdicción sin pago previo alguno tiene raigambre constitucional porque de ese modo se asegura efectivamente a cada persona la posibilidad de recurrir a los estrados de los tribunales y alcanzar un amparo igualitario en el ejercicio de sus derechos. No obstante, generalmente el primer proveído de un tribunal en una causa judicial es aquel que ordena el cumplimiento o integración del aporte de la tasa correspondiente. ¿Se condice esto con el principio de afianzar la justicia y con las garantías constitucionales?

"La efectividad de la protección de la justicia implica la posibilidad de que todos los ciudadanos puedan requerir irrestrictamente y obtener la tutela de sus legítimos derechos sin obstáculo que lo hagan de ilusoria defensa; es que los derechos plasmados en la Constitución no se conciben ya como 'meras' garantías jurídico-formales abstractas, sino derechos plenos y operativos, que exigen efectiva realización material”. . “... cuando la externa y ancha presión dirigida al cumplimiento de pautas fiscalistas (la tasa de justicia, el sellado de reposición) o al

Art. 75 inc. 22 de la Constitución de la Nación Argentina, reformada en 1994.

5 Art. 43 de la Constitución de la Nación Argentina, en el que se consagra el amparo, el habeas data y el habeas corpus como recurso judicial.

6 Art. 11 de la Constitución de la provincia de Buenos Aires.

7 Arts. 15, 16, 20 y ccdtes. de la Constitución de la Provincia de Buenos Aires.

8 Roberto Berizonce. "El costo del proceso". J. A. 1995 -I-, p. 955. 
cobro de derechos profesionales (la deformada voz "honorarios" que tanto tiempo insume a los jueces y tantas fojas carga en los repertorios jurisprudenciales) achicando el contenido propio o específico de la garantía de la defensa, olvida y colisiona con la primera de las directivas que señala que la labor jurisdiccional no se encuentra formalmente dirigida a satisfacer esas exigencias, totalmente secundarias y complicantes de sus fines"?

\section{CONCEPTO DE VULNERABILIDAD}

Vulnerabilidad es la "cualidad de vulnerable". Para que se produzca un daño, debe ocurrir un evento adverso, un riesgo, que puede ser endógeno o exógeno, una incapacidad de respuesta frente a él, y una inhabilidad para adaptarse al nuevo escenario generado por la materialización del riesgo. Considerando estos tres componentes, la vulnerabilidad se torna en una noción útil para examinar diferentes aspectos de la realidad, aunque no existe una definición unívoca. Se usa, en primer lugar, para identificar grupos que se hallan en situación de "riesgo social", es decir, compuestos por individuos que son propensos a presentar conductas relacionadas con la agresión, la delincuencia, la drogadicción, o experimentan diversas formas de daño o tienen desempeños deficientes para la inserción social. En segundo lugar, su uso se da en la delimitación de segmentos de la población que tienen probabilidades de ser afectados por eventos nocivos. El tercer uso, y el más frecuente, se refiere a la identificación de grupos de población que tienen algún atributo común, el que genera problemas relevantes similares. ${ }^{10}$

El vocablo "vulnerabilidad" expresa tanto la exposición al riesgo como la medida de la capacidad de cada unidad para enfrentarlo a través de una respuesta. ${ }^{11}$

La exposición a los riesgos de distinta naturaleza se entiende como los acontecimientos que generan adversidades o secuelas negativas para las personas, hogares, comunidades u organizaciones. La incapacidad de respuesta se vincula con tres aspectos: a) la disponibilidad de recursos con que se cuenta, b) las estrategias para hacer frente a las variaciones, y c) los apoyos de organizaciones.

Históricamente, los términos vulnerabilidad, riesgo, amenaza y catástrofes han sido usados indistintamente, aunque cada uno tiene un significado preciso. Vulnerabilidad ${ }^{12}$ es un concepto múltiple en cuanto a su determinación y diagnóstico, aunque estrictamente su cálculo es imposible. A nivel territorial y tratándose de áreas prioritarias necesitadas de

9 Voto del Dr. Adolfo R. Vázquez - "Marono Héctor vs. Allois Verónica - 26/11/96.

10 Cepal. Vulnerabilidad sociodemográfica: viejos y nuevos riesgos para comunidades, hogares y personas. Sintesis y conclusiones. Brasilia, 2002, pp. 1-2.

11 Cepal. Vulnerabilidad sociodemográfica: viejos y nuevos riesgos para comunidades, hogares y personas. 2002. Separata. Documento electrónico, p.1 y ss.

12 Ignacio Alonso Climent. "Tercer Mundo, desarrollo, desastres y tecnología. Una mirada desde la geografía”. Serie geográfica $\mathrm{N}^{\circ} 10$. Alcalá de Henares, 2002, p. 15. 
intervenciones focalizadas, el término vulnerabilidad alude a una situación aproximada y posible. No posee un valor absoluto sino que dependerá de los tipos y valores de amenaza existentes, de la escala de estudio y de la profundidad y orientación metodológica del mismo.

La vulnerabilidad global como variable integrada del riesgo no responde según la definición propuesta a un único factor de exposición o proximidad al peligro, tampoco a la capacidad de una familia o un país de responder durante el momento de la tragedia o de recuperarse tras la devastación, tampoco a la magnitud de los daños y a la posible existencia de un seguro, o la mayor o menor voluntad política o desembolso monetario que se realice sobre el lugar. La vulnerabilidad de un determinado grupo humano se halla integrada por todos y cada uno de estos factores, constituyendo la pobreza el componente más importante de ella. Si la vulnerabilidad en sí misma constituye un sistema dinámico, el resultado de esa interacción es la incapacidad de sus habitantes para responder ante la presencia de un riesgo determinado, facilitando la ocurrencia del desastre.

Entendido de esa manera el término vulnerabilidad puede prestarse para examinar numerosos procesos sociales, de allí que se haga necesario precisar los alcances conceptuales y explorar analíticamente la cuestión. En ese sentido, la noción de vulnerabilidad se encuentra presente en una amplia gama de disciplinas con diferente aplicación. En ámbitos sociales, la delimitación precisa resulta compleja, aunque en algunas disciplinas es posible identificar los riesgos en forma uniforme. En lo jurídico, el término se refiere a la falta de observancia de los derechos y libertades. En economía es el quehacer profesional a través del análisis de la sensibilidad o la dependencia económica la que muestra el carácter vulnerable de la misma. Otro campo que utiliza ampliamente el concepto es el del estudio de las poblaciones que presenta al menos dos concepciones: una alude a las "conductas de riesgo" y otra a las "situaciones de riesgo", orientada a las decisiones individuales o a los ambientes donde estas se desarrollen.

De esa manera, por vulnerabilidad entendemos “... las características de una persona o grupo desde el punto de vista de su capacidad para anticipar, sobrevivir, resistir y recuperarse del impacto de una amenaza natural...". ${ }^{13}$ La reducción de la vulnerabilidad ante la ocurrencia de los desastres está relacionada con el nivel de desarrollo de las áreas expuestas y afectadas, lo que obliga a considerar estos fenómenos con un enfoque integral. La vulnerabilidad como primer factor en la concreción del riesgo queda integrada por varios ángulos. ${ }^{14}$

13 Canon Blaikie y otros. Vulnerabilidad. El entorno social, político y económico de los desastres. Colombia: La Red, 1996, p. 30.

14 La Red. En: www.desenredando.org. Consultado el 30/01/2013. 


\section{Concepto de las personas en situación de vulnerabilidad conforme a las Reglas de Brasilia}

Se consideran en condición de vulnerabilidad aquellas personas que por razón de su edad, género, estado físico o mental, o por circunstancias sociales, económicas, étnicas o culturales encuentran especiales dificultades para ejercitar con plenitud ante el sistema de justicia los derechos reconocidos por el ordenamiento jurídico.

Podrán constituir causas de vulnerabilidad, entre otras, las siguientes: la edad, la discapacidad, la pertenencia a comunidades indígenas o a minorías, la victimización, la migración y el desplazamiento interno, la pobreza, el género y la privación de libertad.

La concreta determinación de las personas en condición de vulnerabilidad en cada país dependerá de sus características específicas, o incluso de su nivel de desarrollo social y económico.

\section{Edad}

Se considera niño, niña y adolescente a toda persona menor de dieciocho años de edad, salvo que haya alcanzado antes la mayoría de edad en virtud de la legislación nacional aplicable.

Todo niño, niña y adolescente debe ser objeto de una especial tutela por parte de los órganos del sistema de justicia en consideración a su desarrollo evolutivo.

El envejecimiento también puede constituir una causa de vulnerabilidad cuando la persona adulta mayor encuentre especiales dificultades, atendiendo a sus capacidades funcionales, para ejercitar sus derechos ante el sistema de justicia.

\section{Discapacidad}

Se entiende por discapacidad la deficiencia física, mental o sensorial, ya sea de naturaleza permanente o temporal, que limita la capacidad de ejercer una o más actividades esenciales de la vida diaria, que puede ser causada o agravada por el entorno económico y social.

Se procurará establecer las condiciones necesarias para garantizar la accesibilidad de las personas con discapacidad al sistema de justicia, incluyendo aquellas medidas conducentes a utilizar todos los servicios judiciales requeridos y disponer de todos los recursos que garanticen su seguridad, movilidad, comodidad, comprensión, privacidad y comunicación.

\section{Pertenencia a comunidades indigenas}

Las personas integrantes de las comunidades indígenas pueden encontrarse en condición de vulnerabilidad cuando ejercitan sus derechos ante el sistema de justicia estatal. Se promoverán 
las condiciones destinadas a posibilitar que las personas y los pueblos indígenas puedan ejercitar con plenitud tales derechos ante dicho sistema de justicia, sin discriminación alguna que pueda fundarse en su origen o identidad indígenas. Los poderes judiciales asegurarán que el trato que reciban por parte de los órganos de la administración de justicia estatal sea respetuoso con su dignidad, lengua y tradiciones culturales.

Todo ello sin perjuicio de lo dispuesto en la Regla 48 sobre las formas de resolución de conflictos propios de los pueblos indígenas, propiciando su armonización con el sistema de administración de justicia estatal.

\section{Victimización}

A efectos de las presentes Reglas, se considera víctima toda persona física que ha sufrido un daño ocasionado por una infracción penal, incluida tanto la lesión física o psíquica, como el sufrimiento moral y el perjuicio económico. El término víctima también podrá incluir, en su caso, a la familia inmediata o a las personas que están a cargo de la víctima directa.

Se considera en condición de vulnerabilidad aquella víctima del delito que tenga una relevante limitación para evitar o mitigar los daños y perjuicios derivados de la infracción penal o de su contacto con el sistema de justicia, o para afrontar los riesgos de sufrir una nueva victimización. La vulnerabilidad puede proceder de sus propias características personales o bien de las circunstancias de la infracción penal. Destacan a estos efectos, entre otras víctimas, las personas menores de edad, las víctimas de violencia doméstica o intrafamiliar, las víctimas de delitos sexuales, los adultos mayores, así como los familiares de víctimas de muerte violenta.

Se alentará la adopción de aquellas medidas que resulten adecuadas para mitigar los efectos negativos del delito (victimización primaria).

Asimismo se procurará que el daño sufrido por la víctima del delito no se vea incrementado como consecuencia de su contacto con el sistema de justicia (victimización secundaria).

Asimismo, se procurará garantizar, en todas las fases de un procedimiento penal, la protección de la integridad física y psicológica de las víctimas, sobre todo a favor de aquellas que corran riesgo de intimidación, de represalias o de victimización reiterada o repetida (una misma persona es víctima de más de una infracción penal durante un período de tiempo). También podrá resultar necesario otorgar una protección particular a aquellas víctimas que van a prestar testimonio en un proceso judicial. Se pondrá una especial atención en los casos de violencia intrafamiliar, así como en los momentos en que sea puesta en libertad la persona a la que se le atribuye la comisión del delito. 


\section{Migración y desplazamiento interno}

El desplazamiento de una persona fuera del territorio del Estado de su nacionalidad puede constituir una causa de vulnerabilidad, especialmente en los supuestos de los trabajadores migratorios y sus familiares. Se considera trabajador migratorio a toda persona que vaya a realizar, realice o haya realizado una actividad remunerada en un Estado del que no sea nacional. Asimismo, se reconocerá una protección especial a los beneficiarios del estatuto de refugiado, conforme a la Convención sobre el Estatuto de los Refugiados de 1951, así como a los solicitantes de asilo.

También pueden encontrarse en condición de vulnerabilidad los desplazados internos, entendidos como personas o grupos de personas que se han visto forzadas u obligadas a escapar o huir de su hogar o de su lugar de residencia habitual, en particular para evitar los efectos de un conflicto armado, de situaciones de violencia generalizada, de violaciones de los derechos humanos o de catástrofes naturales o provocadas por el ser humano, y que no han cruzado una frontera estatal internacionalmente reconocida.

\section{Pobreza}

La pobreza constituye una causa de exclusión social, tanto en el plano económico como en los planos social y cultural, y supone un serio obstáculo para el acceso a la justicia, especialmente en aquellas personas en las que también concurre alguna otra causa de vulnerabilidad.

Se promoverá la cultura o alfabetización jurídica de las personas en situación de pobreza, así como las condiciones para mejorar su efectivo acceso al sistema de justicia.

\section{Género}

La discriminación que la mujer sufre en determinados ámbitos supone un obstáculo para el acceso a la justicia, que se ve agravado en aquellos casos en los que concurre alguna otra causa de vulnerabilidad.

Se entiende por discriminación contra la mujer toda distinción, exclusión o restricción basada en el sexo que tengan por objeto o resultado menoscabar o anular el reconocimiento, goce o ejercicio por la mujer, independientemente de su estado civil, sobre la base de la igualdad del hombre y la mujer, de los derechos humanos y las libertades fundamentales en las esferas política, económica, social, cultural y civil o en cualquier otra esfera.

Se considera violencia contra la mujer cualquier acción o conducta, basada en su género, que cause muerte, daño o sufrimiento físico, sexual o psicológico a la mujer, tanto en el ámbito público como en el privado, mediante el empleo de la violencia física o psíquica. 
Se impulsarán las medidas necesarias dirigidas a eliminar la discriminación contra la mujer en el acceso al sistema de justicia para la tutela de sus derechos e intereses legítimos, logrando la igualdad efectiva de condiciones.

Se prestará una especial atención en los supuestos de violencia contra la mujer, estableciendo mecanismos eficaces destinados a la protección de sus bienes jurídicos, al acceso a los procesos judiciales y a su tramitación ágil y oportuna.

\section{Pertenencia a minorias}

Puede constituir una causa de vulnerabilidad la pertenencia de una persona a una minoría nacional o étnica, religiosa y lingüística, debiéndose respetar su dignidad cuando tenga contacto con el sistema de justicia.

\section{Privación de libertad}

La privación de la libertad, ordenada por autoridad pública competente, puede generar dificultades para ejercitar con plenitud ante el sistema de justicia el resto de derechos de los que es titular la persona privada de libertad, especialmente cuando concurre alguna causa de vulnerabilidad enumerada en los apartados anteriores.

A efectos de estas Reglas, se considera privación de libertad la que ha sido ordenada por autoridad pública, ya sea por motivo de la investigación de un delito, por el cumplimiento de una condena penal, por enfermedad mental o por cualquier otro motivo. ${ }^{15}$

\section{LOS JOVENES EN CONFLICTO CON LA LEY PENAL}

El problema de los niños y jóvenes que entran en conflicto con la ley penal se agrava en cuanto disminuye la edad de aparición de los primeros actos ilícitos y se incrementa la violencia y la cantidad de los mismos. Más allá de las cuestiones legales de imputabilidad e inimputabilidad que cada país o provincia establezca y las medidas que adopte para la solución de la cuestión, el hecho suscita dos corrientes de opinión opuestas para distintos sectores de la sociedad, sean estos del ámbito jurídico, psicológico, social, religioso, médico.

Una parte de la sociedad se sitúa en el rechazo, el repudio y el pedido de punición para quien ha cometido la falta, sin tener en cuenta la edad. La otra parte, se ubica en la orilla opuesto. La idea es que por tratarse de niños o jóvenes, la vía es la absolución.

En el contexto internacional ha sido una preocupación permanente el trato que se les da a los adolescentes que infringen la Ley Penal. Al ser personas menores de edad, en proceso de

15 XIV Cumbre Judicial Iberoamericana. Brasilia, 4 a 6 de marzo de 2008. 
formación y desarrollo, no pueden recibir el mismo tratamiento que los adultos que cometen un delito.

La Convención sobre los Derechos del Niño, en su artículo 40 se refiere a los derechos de los jóvenes en conflicto con la Ley Penal. En él se subraya que es necesario que los adolescentes que estén acusados o se declaren culpables de haber infringido la ley penal reciban un tratamiento, desde la acusación hasta la sentencia, que implique haber pasado por el proceso de investigación, detención, presentación de los cargos, período de prisión preventiva (en caso de ser necesario), juicio y aplicación de la sanción correspondiente, promoviendo además la educación, atención integral e inserción del adolescente a las familias. El mismo artículo compromete a los Estados Partes a que promuevan el establecimiento de un sistema de justicia aplicable específicamente a las personas que no hayan cumplido los 18 años.

En el plano normativo, Argentina ha recorrido un largo camino desde la incorporación de la Convención de los Derechos del Niño (CDN) a su Derecho interno: otorgamiento de jerarquía constitucional; sanción de nuevas legislaciones provinciales que garantizan los distintos roles y actuaciones administrativas, judiciales y el debido proceso; una creciente y sostenida aplicación de los principios de la CDN por parte de la jurisprudencia local; y la aprobación en 2005 de la Ley Nacional de Protección Integral de los Derechos de las Niñas, Niños y Adolescentes. Así, las bases fundamentales tenidas en cuenta al emprender este análisis sobre la situación actual de los adolescentes en el sistema penal han sido la nueva normativa nacional, la institucionalidad organizativa, la planificación intersectorial plurianual y el establecimiento de sistemas de diagnóstico y monitoreo periódico.

El país aún tiene pendiente la aprobación de una nueva ley penal juvenil plenamente respetuosa de los derechos y garantías de los adolescentes. En la particularidad de las políticas contenidas en la temática de infancia y adolescencia, dicho cambio de abordaje tuvo como hito la sanción de la Ley N 26.061 de Protección Integral de los Derechos de las Niñas, Niños y Adolescentes. La nueva Ley se inscribe en la doctrina de la protección integral de la niñez y la adolescencia. A través de sus disposiciones, apunta a superar el esquema de intervención especializado prevaleciente hasta el momento que, bajo la caracterización de peligro material o moral y/o negligencia, habilitaba la intervención estatal coactiva, cuyo blanco estaba constituido mayoritariamente por niñas, niños y adolescentes de familias pobres con dificultades para la crianza, en el marco de los valores y parámetros dominantes de "normalidad", cuya definición fue modificándose o bien agiornándose a lo largo de la vigencia de la Ley $\mathrm{N}^{\circ} 10.903$ de Patronato de Menores. Finalmente, cabe destacar que la ley crea la figura del Defensor de los Derechos sobre los Niños, Niñas y Adolescentes, quien tendrá a su cargo velar por la protección y la promoción de los derechos de los mismos consagrados en la Convención de los Derechos del Niño. Dicha figura debe ser nombrada 
por el Honorable Congreso de la Nación. El 11 de noviembre de 2007, el Honorable Senado de la Nación dio media sanción a un Proyecto de Resolución Conjunto (Expediente 1453/06 y 2957/07) creando la Comisión Bicameral de Protección Integral de los Derechos de Niñas, Niños y Adolescentes prevista en la Ley N² 6.061 (Expediente $N^{\circ} 1453 / 07$ ), dando un paso ineludible para lograr la designación del Defensor de los Derechos de los Niños, Niñas y Adolescentes en el ámbito nacional.

\section{PRINCIPIOS CONSTITUCIONALES Y DEL DERECHO INTERNACIONAL EN LA JUSTICIA PENAL PARA ADOLESCENTES}

Para un mejor ordenamiento de la exposición y en función de los objetivos perseguidos, se exponen en primer lugar los principios que al respecto figuran en diversos instrumentos internacionales, tales como la Convención sobre los Derechos del Niño (aprobada por la Ley No 23.849 con jerarquía constitucional, artículo 75, inc. 22 C.N. de la Republica Argentina), las Reglas Mínimas de las Naciones Unidas para la administración de la justicia de menores (Reglas de Beijing), las Reglas de las Naciones Unidas para la protección de los menores privados de libertad, las Directrices de las Naciones Unidas para la prevención de la delincuencia juvenil (Directrices de Riad), las Reglas Mínimas de las Naciones Unidas sobre las medidas no privativas de la libertad (Reglas de Tokio), ${ }^{16}$ y las Directrices de Acción sobre el niño en el sistema de justicia penal. ${ }^{17}$

El desarrollo de los principios resulta de utilidad práctica para construir estándares mínimos de referencia que permitan orientar los procesos de adecuación y transformación del actual régimen para los adolescentes infractores y presuntos infractores de la ley penal. Asimismo, los estándares se constituyen en una herramienta útil para evaluar la legislación y los dispositivos vigentes en nuestro país con respecto a los preceptos contenidos en la normativa internacional de derechos humanos.

Utilizando un criterio comparativo, se exponen a continuación dichos estándares, procurando establecer en qué medida la normativa de orden infraconstitucional y los procedimientos vigentes en materia de justicia penal para adolescentes en el territorio nacional se ajustan a ellos.

La Convención sobre los Derechos del Niño (CDN) define como "niño" a toda persona menor de 18 años de edad, y compromete a los Estados Partes a promover el dictado de leyes y procedimientos especiales para los niños de quienes se alegue que han infringido las leyes. Queda configurado de este modo un límite decisivo para regular dos sistemas penales

16 Estas últimas Reglas y Directrices fueron incorporadas al texto normativo para la aplicación del derecho a la libertad (Cfr. art. 19 del Decreto 415/2006 reglamentario de la Ley 26.061 de Protección Integral de los Derechos de las Niñas, Niños y Adolescentes).

17 Anexo de la Resolución 1997/30 del Consejo Económico y Social de Naciones Unidas. 21 de julio de 1997. 
netamente diferenciados: el Sistema Penal para Adolescentes — destinado a los adolescentes infractores y presuntos infractores hasta los 18 años de edad-y el Sistema Penal General —establecido para los infractores mayores de 18 años_- A partir de esta diferenciación, las normas internacionales de derechos humanos establecen que el Sistema de Justicia Penal que intervenga en los delitos cometidos por personas menores de 18 años de edad ${ }^{18}$ debe ser especializado. ${ }^{19}$

El concepto de "especialización" implica:

a) que los órganos judiciales (jueces, fiscales, defensores oficiales) se encuentren capacitados y tengan competencia específica para actuar cuando los delitos son cometidos por adolescentes;

b) que los procedimientos se adapten a las necesidades de los adolescentes, previendo incluso estándares más exigentes en comparación con los vigentes para las personas adultas;

c) que las autoridades administrativas de aplicación del sistema y los establecimientos de ejecución de las penas sean especiales, es decir, diferenciados de los destinados a la población de mayores de 18 años;

d) que las sanciones penales y las medidas alternativas al proceso penal sean diferentes de las del régimen general. ${ }^{20}$

En otros términos, esto significa que mediante la CDN los Estados se han obligado a establecer un régimen jurídico y una serie de instituciones que actúen específicamente en la investigación y sanción de los delitos cometidos por los adolescentes. Asimismo, requiere que los funcionarios integrantes de estos órganos estén especialmente capacitados en cuestiones relativas a los derechos de niños y adolescentes. ${ }^{21}$

Este régimen especial debe ser aplicado a partir de una edad mínima, antes de la cual se presume, sin que se admita prueba en contrario, que los niños no tienen capacidad para infringir las leyes penales.

18 El texto oficial en español de la Convención sobre los Derechos del Niño (CDN) define como "niño" a toda persona de hasta 18 años de edad. Sin embargo, a fin de avanzar en una diferenciación etaria del grupo poblacional al que va dirigido el sistema de justicia penal para adolescentes, se opta en el presente texto por denominarlos como "adolescentes" y considerar "niños" solo a los que están excluidos del sistema penal (Cfr. art. 40, inc. 3.a. de la CDN).

19 Convención Americana de Derechos Humanos (CADH), art. 5.5; CDN, art. 40, inc. 3; Reglas de Beijing, regla 2.3; Directrices de Acción sobre el niño en el sistema de justicia penal, directrices 13.d y 14.a y d. En la directriz 14.d se establece como alternativa la posibilidad de que los tribunales ordinarios tengan procedimientos especiales.

20 Además, deben crearse equipos multidisciplinarios que brinden información a las autoridades judiciales a fin de determinar la sanción penal aplicable en beneficio del adolescente, sin que ello implique menoscabo de su intimidad (Cfr. Reglas de Beijing, regla 16; Reglas de Tokio, regla 7).

21 Reglas de Beijing, regla 22; Directrices de Acción sobre el niño en el sistema de justicia penal, directriz 24; y directriz 58 de las Directrices de Riad. 7 CDN, art. 40, inc. 3.a; Directrices de Acción, directriz 14, inc. c. 
Esto significa que los Estados deben fijar una edad a partir de la cual las personas menores de 18 años de edad sean punibles, en forma completamente diferenciada de los adultos. Al grupo etáreo comprendido entre esa edad mínima y los 18 años de edad, lo denominaremos "adolescente". Por otra parte, las Reglas de Beijing (art. 4.1) establecen que la edad mínima para definir la condición de "adolescente" no debe ser demasiado baja, puesto que deben tenerse en cuenta aquellas circunstancias que afectan su madurez emocional, mental e intelectual, considerando que el discernimiento y la capacidad de comprensión de sus actos están en relación con condiciones históricas y culturales.

El Comité de los Derechos del Niño de Naciones Unidas, en la Observación General N ${ }^{\circ}$ 10, insta a los Estados a no reducir la edad mínima a los 12 años, por no ser internacionalmente aceptable, a elevarla y continuar elevándola. ${ }^{22}$

Al mismo tiempo considera que la fijación de la edad mínima en un nivel más alto, como por ejemplo en los 14 o 16 años de edad, contribuye a lograr el objetivo de adoptar medidas para tratar a los adolescentes sin recurrir a los procedimientos judiciales. ${ }^{23}$

Este límite se debe fijar en función de garantizar de mejor forma la protección de los derechos y garantías de los adolescentes conforme a las políticas de cada Estado. Los hechos ilícitos que cometan los niños menores de la edad mínima fijada por un Estado quedan exentos de la aplicación de una sanción penal por la justicia penal, con el entendimiento de que el eventual procedimiento no judicial respetará plenamente sus derechos humanos y garantías legales. ${ }^{24}$

\section{PRINCIPIO DE LEGALIDAD PENAL}

En las disposiciones internacionales también se establece que la justicia penal para adolescentes solo debe actuar cuando exista la sospecha de que un adolescente cometió un delito. En el artículo 40 de las disposiciones de la Convención sobre los Derechos del Niño se reconoce expresamente el principio de legalidad, por el cual no puede ser iniciado un proceso penal ni condenarse a un adolescente por haber realizado un acto que no se encuentre prohibido en la ley. La finalidad de este principio consiste en evitar que el adolescente sea sancionado por hechos que no constituyen delitos.

22 Comité de los Derechos del Niño, Observación General No 10 (2007), Los Derechos del Niño en la Justicia de Menores, párrafo 33.

23 CDN, art. 40 inc. 3.b. y Comité de los Derechos del Niño, Observación General No 10 (2007), Los Derechos del Niño en la Justicia de Menores, párrafo 33.

24 CDN, art. 40 inc. 3 (b) y Comité de los Derechos del Niño, Observación General No 10 (2007), Los derechos del niño en la Justicia de Menores, párrafo 33. CDN, art. 40 inc. 3 (b) y Comité de los Derechos del Niño, Observación General No 10 (2007), Los Derechos del Niño en la Justicia de Menores, párrafo 33. 
De modo complementario, en las Directrices de Riad se establece que ningún acto que no constituya un delito o que no sea sancionable cuando lo comete un adulto pueda considerarse delito o ser punible cuando lo realiza un adolescente. ${ }^{25}$

\section{GARANTÍAS DE LA JUSTICIA PENAL PARA ADOLESCENTES}

Las disposiciones internacionales y la Constitución Nacional Argentina regulan este aspecto estableciendo que los adolescentes deben contar con iguales garantías penales que los adultos: se exige que el hecho atribuido tenga cierto grado de lesividad, ${ }^{26}$ que sea imputable subjetivamente al autor a título de dolo o de culpa, y que el infractor haya tenido la posibilidad efectiva de conocer la criminalidad del acto y dirigir su conducta para evitar la comisión del delito.

\section{GARANTÍAS PROCESALES DE LA JUSTICIA PENAL PARA ADOLESCENTES}

En la CDN se reconocen en forma expresa una serie de garantías procesales, también previstas en las normas constitucionales:

- Presunción de inocencia. Se establece que se presumirá inocente al adolescente al que se le impute la comisión de un delito mientras no se pruebe su culpabilidad conforme a la ley. La prueba de culpabilidad es condición necesaria para la imposición de penas.

- Información adecuada. El adolescente debe ser informado en forma inmediata de la acusación que se le formula y de su derecho a la defensa. ${ }^{27} \mathrm{La}$ información debe ser comprensible para él, ${ }^{28}$ lo cual implica que el procedimiento se adapte a sus conocimientos y experiencias. En el caso de que no comprenda el idioma, debe ser asistido gratuitamente por un intérprete. ${ }^{29}$

- Asistencia de un abogado defensor y de sus familiares o representante legal. El adolescente debe contar en forma permanente con la asistencia de un abogado defensor ${ }^{30} \mathrm{y}$, teniendo en cuenta su edad, con el apoyo de sus padres o representantes legales, a menos que esta vinculación fuere contraria a su interés superior. ${ }^{31}$

25 Directriz 56

26 Directrices de Riad, directriz 5.

CDN, art. 40, inc. 3.b.ii.

28 Reglas de Beijing, regla 14.2.

29 CDN, art. 40, inc. 3.b.vi; Directrices de Acción sobre el Niño en el Sistema de Justicia Penal, directriz 16 y Reglas de Beijing, reglas 7 y 15.1 .

30 Directrices de Acción sobre el Niño en el Sistema de Justicia Penal, directriz 16 y Reglas de Beijing, reglas 7 y 15.1. Estas reglas establecen que cuando en el país se reconoce el derecho a solicitar la asistencia jurídica gratuita, debe ser provista al adolescente.

${ }^{31} \mathrm{CDN}$, art. 40, inc. 3.b.iii y Reglas de Beijing, reglas 7 y 15.2. 
Debe asegurarse que el adolescente pueda ejercer en forma plena su derecho de defensa, ofreciendo prueba e interrogando a los testigos de cargo. ${ }^{32}$

El adolescente no debe ser obligado a declarar, o sea, no debe ser compelido a suministrar elementos de cargo. ${ }^{33}$

- Derecho a la intimidad. Debe garantizarse en todo momento que se respete la vida privada del adolescente, prohibiendo la difusión de cualquier información que permita identificar a un adolescente acusado de cometer un delito. ${ }^{34}$ Los expedientes de las causas penales deben ser confidenciales, sin que exista posibilidad de que accedan a ellos terceras personas. ${ }^{35}$

- Sobre la duración del proceso penal. La duración de los procesos penales para la toma de decisiones sin demora debe observar tanto la necesaria agilidad en función de la edad del adolescente y de la cercana respuesta judicial frente al hecho, como el pleno respeto a los derechos y garantías de los adolescentes sometidos a proceso penal. ${ }^{36}$

El proceso penal en sí representa cierto grado de coacción que afecta la libertad de una persona, independientemente de que se le aplique la prisión preventiva. Por ello, la duración del proceso penal debe ser razonable, esto significa que no deben producirse dilaciones indebidas. $^{37}$

En el caso excepcional de que la persona se encuentre privada de la libertad por medio de la prisión preventiva, el estándar también debe traducirse en la determinación de un plazo breve y fijado por la ley. Vencido dicho plazo, en función de la excepcionalidad y la máxima brevedad, no debería ser posible prorrogar la extensión de la medida cautelar de coerción personal.

- Derecho al recurso y prohibición de la persecución penal múltiple. En diversos instrumentos de Derecho Internacional incorporados a la Constitución Nacional, se reconoce el derecho del adolescente al recurso, lo cual significa la posibilidad de que recurra ante una autoridad judicial superior, toda decisión judicial que lo afecte. ${ }^{38}$ Además, se reconoce la prohibición de la persecución penal múltiple, que impide que por un mismo hecho delictivo el adolescente sufra una nueva persecución simultánea o sucesiva. ${ }^{39}$

32 CDN, arts. 40, inc. 3.b.iv y 12; Reglas de Beijing, regla 7

$33 \mathrm{CDN}$, art. 40, inc. 3.b.iv y Reglas de Beijing, regla 7.

$34 \mathrm{CDN}$, art. 40, inc. 3.b.vii; Reglas de Beijing, regla 8.1.

35 Reglas de Beijing, art. 21.1; Reglas de Tokio, art. 3.12.

36 Comité de los Derechos del Niño, Observación General No 10 (2007), Los Derechos del Niño en la Justicia de Menores, párrafo 51 “... el tiempo transcurrido entre la comisión de un delito y la respuesta definitiva a ese acto debe ser lo más breve posible. Cuanto más tiempo pase, tanto más probable será que la respuesta pierda su efecto positivo y pedagógico y que el niño resulte estigmatizado...”.

$37 \mathrm{CADH}$, arts. 5.5 y 8.1; Pacto Internacional de los Derechos Civiles y Políticos, arts. 10.2.b. y 14.3.c.

$38 \mathrm{CADH}$, art. 8.2.h; PICDyP, art. 14.5; Reglas de Beijing, regla 7.

$39 \mathrm{CADH}$, art. 8.4; PICDyP, art. 14.7. 


\section{PROGRAMA IBEROAMERICANO SOBRE ACCESO A LA JUSTICIA}

En este marco se ha creado el Programa Iberoamericano de Acceso a la Justicia, a instancia de los Ministros de Justicia de la COMJIB. Se han adherido al Programa, Brasil, Chile, Paraguay, Perú, México, Ecuador, República Dominicana y España. Además, participan la SEGIB y la COMJIB; esta última asume la Secretaría Técnica Ejecutiva del programa. Los días 11 y 12 de abril se celebró en Montevideo la primera reunión del Programa, definiéndose el Plan operativo Anual 2011/2012 y su Reglamento.

En ese sentido, si uno recapitula en la historia, cuando se desarrolló el pensamiento ilustrado en las líneas del Estado de Derecho se tomó en consideración el Sistema Judicial como independiente del Ejecutivo, de jueces imparciales, que aplican leyes dictadas con anterioridad y precisas.

Hay allí dos grandes patrones tradicionales que es necesario desmontar: por una parte, un Estado que en materia de derechos civiles y políticos combinados con derechos económicos, sociales y culturales, muchas veces tiene un rol pasivo de abstención. Por otra parte, se trata de una prerrogativa del Estado, un beneficio, más que propiamente un derecho a ser ejercido.

En términos de que la igualdad ante la ley no es solo igualdad formal sino también igualdad material o real, se introduce explícitamente el principio de no discriminación. El mismo tiene desarrollo después de la Segunda Guerra Mundial, y una transformación institucional en que los países han creado Tribunales Constitucionales, y en los que no, se cambian las competencias de las Cortes Supremas de manera de asegurarles una mayor presencia en garantías de derechos fundamentales —en términos normativos- y el fortalecimiento del acceso a la justicia.

En la justicia oficial es importante la creación o fortalecimiento de mecanismos de protección de derechos fundamentales, tales como los recursos de amparo, con su jurisprudencia, o la acción de tutela en otros países. Otro aspecto relevante es el proceso de ratificación de tratados de derechos humanos por países iberoamericanos. Todos los Estados latinoamericanos en sentido estricto, no incluyendo el Caribe, han ratificado los tratados de derechos humanos y son reconocedores de la jurisdicción de la Corte, además del Tratado de Derechos Civiles y Políticos, y de los sistemas de la ONU. Ello produce cierta retroalimentación entre las constituciones y los tratados ratificados, lo que permite el uso por los tribunales locales de estos tratados. Esto ha sido variable en los casos de Argentina, Colombia y Costa Rica. En otros países, el desarrollo es específico. En Chile modificaron su jurisprudencia, pero no simétricamente. En la aceptación de derechos fundamentales se ha progresado en violaciones de derechos humanos del pasado pero no en violación de derechos humanos actuales. En algunos aspectos, el desarrollo es mayor y en otros limitados. 
En términos precisos, el Derecho Internacional de los DDHH ha desarrollado criterios en acceso a la justicia. En Europa, existe un caso en Irlanda, de hace varias décadas, que se refiere a la obligación del Estado de prestar asistencia letrada en un juicio de divorcio. Según la legislación interna, no era obligación estatal proveer abogado, pero el Tribunal Europeo de Derechos Humanos entendió que era necesario en esos casos por la complejidad del asunto. ${ }^{40}$ También en el Tribunal Europeo de Derechos Humanos hay casos en que el acceso a la justicia no es meramente formal, de consagración en la Constitución o ley, sino que se debe reflejar en la práctica y no debe ser impedido injustificadamente por la autoridad estatal. El Tribunal Europeo de Derechos Humanos tiene facultad para fiscalizar la implementación de acceso a la justicia en los países miembros. En el sistema interamericano, en la opinión consultiva número 11 de la Corte Interamericana de $\mathrm{DDHH}$, el agotamiento de recursos internos es un requisito para llevar denuncias a sede internacional, cuando subsidiariamente no pueden o no quieren los órganos estatales internos. Se manejaron una serie de hipótesis que dificultaban el acceso a la justicia a la ciudadanía, entre ellas la persona que por falta de recursos no podía tener asesoría jurídica y el Estado no se la ofrecía. El tribunal en esta opinión consultiva expreso de manera general que cuando eso ocurría, si la persona no tenía representación jurídica por motivos económicos, se puede saltar la vía interna y acudir directamente a los organismos internacionales y no directamente a la Corte. La regla de agotamiento de recursos internos contempla una serie de excepciones, y una de ellas es la falta de debido proceso o cuando a la persona se la ha impedido agotar los referidos recursos.

Un aspecto importante en la justicia oficial de los países iberoamericanos ha sido la ratificación de tratados de derechos humanos, la creación o fortalecimiento de mecanismos de protección de derechos fundamentales a nivel internacional, e internamente, a través de los recursos o acciones constitucionales como las acciones de amparo y protección, o la acción de tutela en algunos países.

Asimismo, en materia de acceso a la justicia ha habido una influencia de la esfera internacional a la nacional, sin perjuicio de los problemas de implementación y de efectividad que han permitido modificar un conjunto de mitos incorporados en los patrones culturales judiciales, entre ellos la pasividad del Estado en materia de derechos civiles, que no organiza todo su aparato para proteger los derechos humanos. La idea de que el acceso a la justicia es un beneficio y no propiamente un derecho, y los criterios de interpretación literal de la ley, que constriñen a los jueces a la hora de decidir los casos, traen aparejado que el mismo se torne ilusorio. La jurisprudencia internacional es más amplia al momento de interpretar el acceso a la justicia como un verdadero derecho. Existen al respecto una serie de elementos de interpretación que deben ser aplicados por los jueces nacionales a la hora de respetar los derechos fundamentales.

40 Airey c/ Irlanda 09/10/1979. Boletín de Jurisprudencia TEDH 
Al respecto puede mencionarse la facultad con la que cuenta el Tribunal Europeo de Derechos Humanos para fiscalizar la implementación de acceso a la justicia en los países miembros. En el sistema Interamericano, existen diversas opiniones consultivas de la Corte Interamericana de Derechos Humanos, que en casos concretos y en referencia al agotamiento de recursos internos ha manejado una serie de hipótesis respecto a dificultades en la temática en desarrollo de la ciudadanía. Hay casos de personas que por falta de recursos no pueden tener asesoría jurídica y el Estado no se la brinda. También existen letrados amenazados por tomar ciertas causas, lo cual en la práctica desencadena la inexistencia de representación letrada. Otro ejemplo de mención resulta la negativa de asistencia gratuita al inmigrante indocumentado. La Corte ha señalado constantemente que el Estado debe garantizar que el acceso a la justicia sea no solo formal sino real.

La Corte ha enfatizado el derecho del acceso a la justicia de distintos colectivos, como los de niños, niñas, mujeres y trabajadores, en el sentido de garantizar recursos efectivos y mecanismos eficientes para ejecutar la decisiones de las sentencias. Hay un desarrollo jurisprudencial importante sobre protección judicial, en cuanto al deber de respetar los derechos humanos, que tienen impacto en este tema.

En el particular caso de violencia contra la mujer, la Corte Interamericana de Derechos Humanos ha señalado que el acceso a la justicia no se limita solo a los recursos formales sino que además estos deben ser idóneos para investigar, sancionar y reparar la conducta denunciada. La CIDH ha desarrollado un análisis entre la Convención de "Belem do Para" para prevenir, sancionar y erradicar la violencia contra la mujer y la Convención Americana sobre Derechos Humanos, y cómo ello se conecta con el acceso a la justicia, profundizando en una serie de mecanismos o herramientas que deben ser implementados por los Estados a fin de fortalecer los derechos de las mujeres víctimas de la violencia.

A nivel de la Organización de Naciones Unidas, la Declaración Universal de Derechos Humanos, los Pactos de Derechos Civiles y Políticos, y de Derechos Económicos, Sociales y Culturales con sus respectivos protocolos, consagran derechos relacionados al acceso a la justicia como la igualdad ante la ley, la no discriminación, el derecho a ser oído sin demora indebida y ante un juez imparcial, entre otros. Existe, además, una serie de instrumentos específicos tales como la independencia de la judicatura, directrices de las funciones de los fiscales, entre otros, que incorporan elementos de carácter general que podrían dar lugar a una interpretación sistemática. Por otra parte, existe una serie de avances en materia de reformas para los procesos penales y civiles.

La reforma procesal ha avanzado hacia el acceso a la justicia en la gran mayoría de los países iberoamericanos, dejando atrás el arcaico sistema inquisitivo, abriéndose al sistema acusatorio, con la inmediación, oralidad y publicidad como actos esenciales. Si bien existen 
dificultades aún en algunos de sus aspectos, la inmediación como principio formativo de este sistema viene a asegurar mejores condiciones de acceso a la justicia.

En materia procesal civil, que aún genera menor interés en Iberoamérica, se han tomado medidas para reducir la demora judicial, la simplificación de procedimientos, pero sin llegar a un proceso de reforma generalizado como esta ocurriendo en el ámbito penal.

En la temática de justicia indígena, existe una importante disparidad en la regulación legal entre los Estados. Así, aun cuando muchos países reconocen a estos pueblos en sus Constituciones, no hay uniformidad en la forma del reconocimiento, ni tampoco del tratamiento judicial de los derechos indígenas. Mientras en algunos países hay jurisdicciones especiales y garantías, tales como traductores o defensores que manejen la lengua indígena, en otros resulta meramente formal y no se traduce en herramientas eficientes para su verdadero reconocimiento.

\section{LA JURISPRUDENCIA DE LA CORTE INTERAMERICANA DE DERECHOS HUMANOS EN MATERIA DE ACCESO A LA JUSTICIA E IMPUNIDAD}

Reiteradamente, a lo largo de muchos años, tanto en uso de su función consultiva como jurisdiccional, la Corte Interamericana de Derechos Humanos (en adelante "la Corte", "la Corte Interamericana" o "el Tribunal") ha afirmado, en relación con la democracia, los derechos humanos y el Estado de Derecho, que "en una sociedad democrática los derechos y libertades inherentes a la persona, sus garantías y el Estado de Derecho constituyen una tríada, cada uno de cuyos componentes se define, completa y adquiere sentido en función de los otros".

Específicamente, temas como el acceso a la justicia y la impunidad han estado permanentemente presentes en su tarea convencional de interpretar y aplicar la Convención Americana sobre Derechos Humanos (en adelante "la Convención", "la Convención Americana", "Pacto de San José de Costa Rica", o la "CADH"), al considerar los casos que le han sido sometidos a su consideración por la Comisión Interamericana de Derechos Humanos (en adelante "la Comisión" o "la Comisión Interamericana"). ${ }^{41}$

El acceso a la justicia puede ser entendido como la posibilidad de toda persona, independientemente de su condición económica o de otra naturaleza, de acudir al sistema previsto para la resolución de conflictos y vindicación de los derechos protegidos de los cuales es titular. Es decir que por este principio podemos entender la acción, ante una controversia

41 Corte I.D.H., El Hábeas Corpus Bajo Suspensión de Garantías (arts. 27.2, 25.1 y 7.6 Convención Americana sobre Derechos Humanos). Opinión Consultiva OC-8/87 del 30 de enero de 1987. Serie A No. 8, párr. 26; y Corte I.D.H., Garantías Judiciales en Estados de Emergencia (arts. 27.2, 25 y 8 Convención Americana sobre Derechos Humanos). Opinión Consultiva OC-9/87 del 6 de octubre de 1987. Serie A No. 9. 
o la necesidad de esclarecimiento de un hecho, de poder acudir a los medios previstos por los ordenamientos jurídicos nacionales e internacionales para su respectiva resolución. Tanto a nivel nacional como internacional, este término ha sido últimamente visto como un equivalente al mejoramiento de la administración de justicia, siendo este una forma de ejecución de dicho principio. Recordemos que es en el campo de la administración de justicia donde se define la vigencia de los derechos fundamentales en las sociedades contemporáneas, donde se prueba si las libertades y garantías enunciadas en los diferentes instrumentos de Derecho internacional tienen o no aplicación real en los ámbitos internos e internacionales de protección.

La Corte ha establecido que el acceso a la justicia se encuentra consagrado en los artículos 8.1 y 25 de la Convención Americana.

El artículo 8.1 del Pacto de San José de Costa Rica dispone:

"Toda persona tiene derecho a ser oída, con las debidas garantías y dentro de un plazo razonable, por un juez o autoridad competente, independiente e imparcial, establecida con anterioridad por la ley, en la sustanciación de cualquier acusación penal formulada contra ella, o para la determinación de sus derechos y obligaciones de orden civil, laboral, fiscal o de cualquier otro carácter”.

Esta disposición es clara, y según ella, los Estados no deben interponer trabas a las personas que acudan a los jueces o a los tribunales en busca de que sus derechos sean protegidos o determinados. Consecuentemente, cualquier norma o medida estatal, en el orden interno, que dificulte de cualquier manera, una de las cuales puede ser la imposición de costos, el acceso de los individuos a los tribunales, y que no esté justificada por necesidades razonables de la propia administración de justicia, debe entenderse como contraria a la citada norma convencional.

Por su parte, el artículo 25 de la Convención Americana, que también garantiza el acceso a la justicia, dispone:

1. Toda persona tiene derecho a un recurso sencillo y rápido o a cualquier otro recurso efectivo ante los jueces o tribunales competentes, que la ampare contra actos que violen sus derechos fundamentales reconocidos por la Constitución, la ley o la presente Convención, aun cuando tal violación sea cometida por personas que actúen en ejercicio de sus funciones oficiales.

2. Los Estados Partes se comprometen:

a) a garantizar que la autoridad competente prevista por el sistema legal del Estado decidirá sobre los derechos de toda persona que interponga tal recurso; 
b) a desarrollar las posibilidades de recurso judicial; y

c) a garantizar el cumplimiento, por las autoridades competentes, de toda decisión en que se haya estimado procedente el recurso.

El artículo de referencia establece la obligación positiva del Estado de conceder a todas las personas bajo su jurisdicción un recurso judicial efectivo contra actos violatorios de sus derechos fundamentales, derechos fundamentales que pueden estar reconocidos en la Convención Americana o por la propia ley interna.

Asimismo, la Corte ha señalado en reiteradas oportunidades que la garantía de un recurso efectivo constituye una de los pilares básicos, no solo de la Convención Americana, sino del propio Estado de Derecho en una sociedad democrática en el sentido de la Convención.

También ha dispuesto la Corte, desde sus primeras sentencias contenciosas en los casos Velásquez Rodriguez y Godínez Cruz, que para cumplir con lo dispuesto por el artículo 25 no basta con la existencia formal de los recursos, sino que estos deben ser adecuados y efectivos para remediar la situación jurídica infringida. O sea, cualquier norma o medida que impida o dificulte hacer uso del recurso de que se trata constituye una violación del derecho de acceso a la justicia, según lo dispone el artículo 25 de la Convención.

Al respecto, en el caso Barrios Altos contra el Perú, la Corte se refirió a la obligación de los Estados partes en la Convención de garantizar el libre y pleno ejercicio de los derechos reconocidos en la Convención Americana a toda persona sujeta a su jurisdicción.

En los casos Velásquez Rodríguez y Godínez Cruz la Corte precisó las implicancias de esta garantía en relación con la vigencia de los derechos considerados inderogables y cuya afectación constituye una grave violación de los derechos humanos, así como la posibilidad de la comisión de un delito contra la humanidad. Asimismo, el tribunal estableció que el deber de investigar y sancionar a los responsables de violaciones a los derechos humanos implicaba a prohibición de dictar cualquier legislación que tuviera por efecto conceder impunidad a los responsables de hechos de la gravedad señalada. ${ }^{42}$

En este caso, la Corte Interamericana determinó la responsabilidad internacional del Estado no solo por la violación del derecho a la vida e integridad personal derivada de los hechos del caso, sino además por el dictado de dos leyes de amnistía, lo que constituyó la violación del derecho a las garantías judiciales (art. $8 \mathrm{CADH}$ ), del derecho a la protección judicial (art. 25 $\mathrm{CADH}$ ) y al deber de adoptar disposiciones de Derecho interno (art. $2 \mathrm{CADH}$ ).

42 Corte I.D.H., Caso Velásquez Rodríguez. Sentencia del 29 de julio de 1988. Serie C No. 4; y Corte I.D.H., Caso Godinez Cruz. Sentencia del 20 de enero de 1989. Serie C No. 5. 
Cabe señalar, además, que si bien la Corte se pronunció en este caso sobre la validez de la auto-amnistía, analizando dicha legislación por sus efectos y no por su origen, es válida la consideración de que dicha prohibición rige tanto para el propio gobierno que cometió las violaciones así como para el gobierno democrático reestablecido. En este sentido, la Corte consideró que son inadmisibles las disposiciones de amnistía, las disposiciones de prescripción y el establecimiento de excluyentes de responsabilidad que pretendan impedir la investigación y sanción de los responsables de las violaciones graves de los derechos humanos tales como la tortura, las ejecuciones sumarias, extralegales o arbitrarias y las desapariciones forzadas, todas ellas prohibidas por contravenir derechos inderogables reconocidos por el Derecho Internacional de los Derechos Humanos. Asimismo, la Corte estimó necesario enfatizar que, a la luz de las obligaciones generales consagradas en los artículos 1.1 y 2 de la Convención Americana, los Estados Partes tienen el deber de tomar las providencias de toda índole para que nadie sea sustraído de la protección judicial y del ejercicio del derecho a un recurso sencillo y eficaz, en los términos de los artículos 8 y 25 de la Convención. Por ello, los Estados Partes en la Convención que adopten leyes que tengan este efecto, como lo son las leyes de auto-amnistía, incurren en una violación de los artículos 8 y 25 en concordancia con los artículos 1.1 y 2 de la Convención. Las leyes de autoamnistía conducen a la indefensión de las víctimas y a la perpetuación de la impunidad, por lo que son manifiestamente incompatibles con la letra y el espíritu de la Convención Americana. Este tipo de leyes impide la identificación de los individuos responsables de violaciones a derechos humanos, ya que se obstaculiza la investigación y el acceso a la justicia e impide a las víctimas y a sus familiares conocer la verdad y recibir la reparación correspondiente. Como consecuencia de la manifiesta incompatibilidad entre las leyes de autoamnistía y la Convención Americana sobre Derechos Humanos, las mencionadas leyes carecen de efectos jurídicos y no pueden seguir representando un obstáculo para la investigación de los hechos que constituyen este caso ni para la identificación y el castigo de los responsables, ni puedan tener igual o similar impacto respecto de otros casos de violación de los derechos consagrados en la Convención Americana acontecidos en el Perú. ${ }^{43}$

En este caso, la Corte haciendo uso libre y pleno, como le corresponde, de los poderes inherentes a su función judicial, dispuso por primera vez en un caso de allanamiento, además de admitir el reconocimiento de responsabilidad internacional por parte del Estado demandado, el establecimiento de las consecuencias jurídicas de dicho allanamiento.

Estas consideraciones de la Corte Interamericana buscan superar un obstáculo que los órganos internacionales de supervisión de los derechos humanos todavía no han logrado transponer: la impunidad, con la consecuente erosión de la confianza de la población en las

43 Corte I.D.H., Caso Barrios Altos. Sentencia del 14 de marzo de 2001. Serie C No. 75. 
instituciones públicas. Recordemos, al respecto, que el principal documento adoptado por la II Conferencia Mundial de Derechos Humanos (1993) exhortó a los Estados a "derogar la legislación que favorezca la impunidad de los responsables de violaciones graves de los derechos humanos, (...) y sancionar esas violaciones (...)" ${ }^{\prime 44}$

\section{ACCESO A LA JUSTICIA PARA LAS PERSONAS CON DISCAPACIDAD}

ADAJUS es el Programa Nacional de Asistencia para las Personas con Discapacidad en sus Relaciones con la Administración de Justicia, y fue creado en Argentina, con el fin de cumplir con la Convención sobre los Derechos de las Personas con Discapacidad y su Protocolo Facultativo, y en particular con la obligación de la Argentina como Estado Parte de garantizar el efectivo acceso a la justicia de las personas con discapacidad (PCD).

El Programa depende de la Secretaría de Justicia de la Nación y su objetivo se enmarca dentro de las políticas de inclusión social que lleva adelante el Gobierno Nacional, con el objetivo de fortalecer los derechos de las PCD a través de procedimientos adecuados, comunicación e información.

Las PCD se encuentran con diferentes obstáculos que dificultan el pleno ejercicio de sus derechos cuando participan de los procesos judiciales o administrativos, sea por dificultades en el acceso a la información sobre sus derechos y la forma de ejercerlos, por trato inadecuado por parte de las fuerzas de seguridad en los diferentes procedimientos, por la modalidad en que los operadores judiciales interactúan con ellas, por abordajes incorrectos en los procedimientos periciales por el desconocimiento por parte de los actores judiciales de la normativa vigente sobre discapacidad, entre otras situaciones.

ADAJUS está dirigido a las PCD, operadores judiciales, agentes penitenciarios, fuerzas de seguridad, funcionarios de la administración pública, colegios profesionales y organizaciones de la sociedad civil, y sus funciones son las siguientes:

* Orientación, asistencia técnica, derivación, y elaboración de guías y protocolos de intervención.

* Capacitación a los actores del Poder Judicial, colegios profesionales y funcionarios de la Administración Pública, como así también al sector privado que lo solicite.

* Conocer e intervenir en la situación de las PCD en situación de encierro.

* Adecuar la intervención de los cuerpos periciales en los procesos judiciales o preliminares que involucren a las PCD.

44 Naciones Unidas, Declaración y Programa de Acción de Viena (1993), Parte II, párr. 60. 
* Ofrecer asistencia técnica para adecuaciones y reformas legislativas.

* Promover la cooperación interinstitucional.

* Impulsar la cooperación y el intercambio de experiencias con instituciones y organismos internacionales.

El Programa se encuentra bajo la coordinación de la Perito Oficial Intérprete, Mabel Aurora Remón, y el mismo presenta un abordaje interdisciplinario que permite trabajar transversalmente la temática de discapacidad. ${ }^{45}$

\section{DERECHO COMPARADO: ACCESO A LA JUSTICIA EN LA CONSTITUCIÓN ESPAÑOLA DE 1978}

\section{Artículo 24}

1. Todas las personas tienen derecho a obtener la tutela efectiva de los jueces y tribunales en el ejercicio de sus derechos e intereses legítimos, sin que, en ningún caso, pueda producirse indefensión.

2. Asimismo, todos tienen derecho al Juez ordinario predeterminado por la ley, a la defensa y a la asistencia de letrado, a ser informados de la acusación formulada contra ellos, a un proceso público sin dilaciones indebidas y con todas las garantías, a utilizar los medios de prueba pertinentes para su defensa, a no declarar contra sí mismos, a no confesarse culpables y a la presunción de inocencia.

La ley regulará los casos en que, por razón de parentesco o de secreto profesional, no se estará obligado a declarar sobre hechos presuntamente delictivos.

\section{a. Medidas constitucionales de protección}

El derecho a la tutela judicial efectiva, el derecho a la defensa y los demás derechos y garantías procesales recogidas en el artículo 24 de la Constitución Española gozan de las siguientes medidas de protección, establecidas por la propia Constitución:

Cualquier ciudadano puede recabar la tutela de los derechos a la tutela judicial efectiva, a la defensa y los demás derechos y garantías procesales recogidas en el artículo 24 de la Constitución española, ante los Tribunales ordinarios, por un procedimiento basado en los principios de preferencia y sumariedad (art. 53.2 de la Constitución Española).

Cualquier ciudadano puede acudir, tras el cumplimiento de los requisitos y tramitaciones

45 Decreto $N^{\circ}$ 1.375/11 del 8 de septiembre de 2011.Publicado en Boletín Oficial el día 16 de septiembre de 2011. 
establecidas para ello, al recurso de amparo ante el Tribunal Constitucional para la protección de los derechos a la tutela judicial efectiva, a la defensa y los demás derechos y garantías procesales recogidos en el artículo 24 de la Constitución (art. 53.2 y art. 161.1.b de la Constitución Española).

Cabe el recurso de inconstitucionalidad contra las leyes y disposiciones normativas con fuerza de ley que vulneren los derechos a la tutela judicial efectiva, a la defensa y los demás derechos y garantías procesales recogidos en el artículo 24 de la Constitución Española (artículo 53.1 y artículo 161.1.a de la Constitución Española).

El Defensor del Pueblo se encuentra designado, en virtud de lo establecido en el artículo 54 de la Constitución Española, como alto comisionado de las Cortes Generales para la defensa de los derechos recogidos en el Título I de la Constitución, encuadrándose el artículo 24 de la Constitución dentro del mencionado Título I.

Solo por ley, que en todo caso deberá respetar el contenido esencial de los derechos a la tutela judicial efectiva, a la defensa y los demás derechos y garantías procesales recogidos en el artículo 24 de la Constitución Española, podrá regularse el ejercicio de tales derechos (art. 53.1 de la Constitución Española).

El desarrollo normativo de los derechos a la tutela judicial efectiva, a la defensa y los demás derechos y garantías procesales recogidos en el artículo 24 de la Constitución Española debe realizarse mediante Ley Orgánica (art. 81.1 de la Constitución Española), que requiere un especial consenso parlamentario al exigirse, para su aprobación, modificación o derogación, mayoría absoluta del Congreso (art. 81.2 de la Constitución Española).

Se prohíbe la adopción de Decretos-Leyes que afecten a los derechos a la tutela judicial efectiva, a la defensa y los demás derechos y garantías procesales recogidos en el artículo 24 de la Constitución Española (al igual que a cualquier otro derecho, deber o libertad recogida en el Título I de la Constitución), aun en los supuestos de extraordinaria y urgente necesidad en los que, para la regulación de otras materias, sí resulta procedente recurrir a los DecretosLeyes (art. 86.1 de la Constitución Española).

El artículo 24 de la Constitución Española (al igual que ocurre con los demás preceptos del Capítulo II del Título I de la Constitución) vincula directamente a las Administraciones Públicas (sin necesidad de mediación del legislador ordinario ni de desarrollo normativo alguno), tal y como se desprende de la STC 80/1982.

Cualquier modificación de la regulación que establece la Constitución Española para los derechos a la tutela judicial efectiva, a la defensa y los demás derechos y garantías procesales recogidos en su artículo 24 debería canalizarse a través de la vía de reforma constitucional 
gravada que establece el artículo 168 de la Constitución Española y que requiere de un gran consenso social ya que exige la aprobación de la correspondiente propuesta por mayoría de dos tercios de cada cámara parlamentaria (Congreso de los Diputados y Senado), la posterior disolución de las Cortes Generales, la posterior celebración de elecciones generales, la nueva ratificación de la propuesta de modificación por mayoría de dos tercios de las cámaras parlamentarias formadas tras las correspondientes elecciones y, por último, la ratificación de la propuesta de modificación mediante referéndum.

\section{b. Gratuidad}

El art. 119 del texto constitucional proclama un derecho a la gratuidad de la justicia en los casos y en la forma en los que el legislador determine. Es un derecho prestacional y de configuración legal cuyo contenido y concretas condiciones de ejercicio corresponde delimitar al legislador atendiendo a los intereses públicos y privados implicados y a las concretas disponibilidades presupuestarias.

El reconocimiento de esta amplia libertad de configuración legal resulta manifiesto en el primer inciso del art. 119 al afirmar que "la justicia será gratuita cuando así lo disponga la ley”. El legislador podrá atribuir el beneficio de justicia gratuita a quienes reúnan las características y requisitos que considere relevantes, podrá modular la gratuidad en función del orden jurisdiccional afectado — penal, laboral, civil, etc. — o incluso del tipo concreto de proceso y, por supuesto, en función de los recursos económicos de los que pueda disponer en cada momento.

Sin embargo, el mismo precepto deja claro el contenido constitucional indisponible que acota la facultad de libre disposición del legislador. Lo hace en el segundo inciso al señalar que "en todo caso" la gratuidad se reconocerá "a quienes acrediten insuficiencia de recursos para litigar”.

Según la doctrina del Tribunal, entre otras, en sus sentencias 77/1983 o 216/1988, la gratuidad de la justicia se configura como un derecho subjetivo cuya finalidad es asegurar la igualdad de defensa y representación procesal al que carece de medios económicos, constituyendo al tiempo una garantía para los intereses de la Justicia.

Como ha señalado el Tribunal Constitucional (STC 16/1994, del 20 de enero), el legislador puede fijar este concepto normativo relativamente abierto a partir de criterios objetivos como el de una determinada cantidad de ingresos, u optar por un sistema de arbitrio judicial, dejándolo a la decisión discrecional de los jueces o de estos y otras instancias, o puede utilizar fórmulas mixtas, limitándose a establecer las pautas genéricas que debe ponderar el Juez al conceder o denegar las solicitudes de gratuidad. 
Con todo, el núcleo indisponible supone que la justicia gratuita debe reconocerse a quienes no puedan hacer frente a los gastos originados por el proceso (incluidos los honorarios de los abogados y los derechos arancelarios de los procuradores, cuando su intervención sea preceptiva o necesaria en atención a las características del caso) sin dejar de atender a sus necesidades vitales y a las de su familia.

Deben sufragarse los gastos procesales a quienes, de exigirse ese pago, se verían en la alternativa de dejar de litigar o poner en peligro el nivel mínimo de subsistencia personal o familiar.

El Tribunal Europeo de Derechos Humanos ha tenido ocasión de pronunciarse acerca de este derecho en los casos Airey (sentencia del 9 de octubre de 1979) y Pakelli (sentencia del 25 de abril de 1983).

Este precepto constitucional aparece desarrollado en la Ley 1/1996, del 10 de enero, de Asistencia Jurídica Gratuita. Frente a la situación de dispersión existente con anterioridad, la Ley 1/1996 unificó el procedimiento, evitando así tener que acudir a las diferentes leyes reguladoras del procedimiento en cada orden jurisdiccional.

Como señala su exposición de motivos, suprimidas por la Ley 25/1986 las tasas judiciales, el núcleo de los costes económicos derivados del acceso a la tutela judicial viene determinado por la intervención en el mismo, por imperativo legal en la mayor parte de las ocasiones, de profesionales especializados en la defensa y representación de los derechos e intereses legítimos. En efecto, una vez que el Estado ha renunciado a la percepción de cualquier cantidad por el acceso al aparato judicial, son los honorarios de abogados, de procuradores y, en su caso, de cualesquiera otros profesionales, así como el coste de la obtención de las pruebas documentales o periciales necesarias, los que implican un coste económico inasumible para los ciudadanos que no disponen de los recursos económicos necesarios para hacerles frente.

La previsión constitucional del artículo 119 ha sido ya objeto de desarrollo por la Ley Orgánica 6/1985 del Poder Judicial, que en sus artículos 20.2 y 440.2 recoge el mandato constitucional y remite, para la regulación del sistema de justicia gratuita, a la ley ordinaria. En virtud de esta reserva de ley, corresponde al legislador ordinario dar cumplimiento a la encomienda constitucional de que se articule un sistema de justicia gratuita para aquellos que carezcan de recursos.

Bajo la amplia libertad de configuración legal que se deriva del art. 119 de la CE, la Ley establece un doble criterio para el reconocimiento del derecho: un criterio objetivo basado en la situación económica de los solicitantes complementado por un mecanismo flexible de apreciación subjetiva que posibilita efectuar el reconocimiento excepcional del derecho a personas cuya situación económica excede del módulo legal pero que, sin embargo, afrontan 
unas circunstancias de una u otra índole que deben ser ponderadas y que hacen conveniente ese reconocimiento.

A pesar de que la evaluación del cumplimiento de los requisitos para gozar del derecho a la asistencia jurídica gratuita no es en sentido estricto una función jurisdiccional, así se ha mantenido tradicionalmente en nuestra legislación procesal.

La Ley actual, lejos de esa concepción, configura dicha función como una actividad esencialmente administrativa. La traslación del reconocimiento del derecho a sede administrativa responde a dos motivos: en primer término se descarga a los juzgados y tribunales de una tarea que queda fuera de los márgenes constitucionales del ejercicio de la potestad jurisdiccional, y en segundo lugar se agiliza la resolución de las solicitudes de los ciudadanos mediante una tramitación sumaria y normalizada.

El reconocimiento del derecho pasa, por tanto, a convertirse en una función que descansa sobre el trabajo previo de los colegios profesionales, que inician la tramitación ordinaria de las solicitudes, analizan las pretensiones y acuerdan designaciones o denegaciones provisionales, y, por otra parte, sobre la actuación de unos órganos administrativos, las comisiones de asistencia jurídica gratuita, como órganos formalmente responsables de la decisión final, y en cuya composición se hallan representadas las instancias intervinientes en el proceso. La Ley garantiza el control judicial sobre la aplicación efectiva del derecho, posibilitando el correspondiente recurso.

La Ley de Asistencia Jurídica Gratuita ha sufrido modificaciones de importancia desde su entrada en vigor. En primer lugar, debe destacarse la operada por Ley 16/2005, del 18 de julio, que modifica la Ley 1/1996, de asistencia jurídica gratuita, para regular las especialidades de los litigios transfronterizos civiles y mercantiles en la Unión Europea, incorporándose así al ordenamiento español la Directiva 2003/8/CE del Consejo, del 27 de enero de 2003, destinada a mejorar el acceso a la justicia en los litigios transfronterizos mediante el establecimiento de reglas mínimas comunes relativas a la justicia gratuita para dichos litigios.

Pero la ley 16/2005 aprovechó también la ocasión para, en aras de mejorar la protección dispensada a las personas con discapacidad, en la línea que ya han seguido otras normas (como la Ley 51/2003, del 2 de diciembre, de Igualdad de Oportunidades, no Discriminación y Accesibilidad Universal de las Personas con Discapacidad), para incluir en el ámbito de aplicación de la Ley a tales personas con discapacidad y a quienes las tengan a su cargo, así como a las asociaciones que tengan como finalidad la protección de personas con discapacidad. Asimismo, para hacer extensiva la justicia gratuita a los extranjeros que se encuentren en España, aun cuando no residan legalmente en el país, cuando acrediten insuficiencia de recursos para litigar, incorporando así la doctrina de la sentencia del Tribunal 
Constitucional 95/2003, del 22 de mayo. Otra de las más relevantes reformas de la Asistencia Jurídica gratuita se ha llevado a cabo por ley 13/2009 del 3 de noviembre, de reforma de la legislación procesal para la implantación de la nueva oficina judicial. La reforma exige que sea el Secretario Judicial en determinados casos el que inste a los colegios profesionales a designar el abogado de oficio y realice la preceptiva comunicación entre el órgano jurisdiccional y los colegios; y permite la suspensión excepcional del procedimiento judicial por parte del órgano jurisdiccional, para evitar la indefensión eventualmente provocada durante la tramitación de la petición y obtención de justicia gratuita. La Ley garantiza el control judicial sobre la aplicación efectiva del derecho, posibilitando el correspondiente recurso. ${ }^{46}$

\section{c. Actualidad}

BOLETÍN OFICIAL DEL ESTADO Núm. 280. Miércoles 21 de noviembre de 2012, 14301 Ley 10/2012, del 20 de noviembre, por la que se regulan determinadas tasas en el ámbito de la Administración de Justicia y del Instituto Nacional de Toxicología y Ciencias Forenses. $^{47}$

Las tasas alcanzarán ahora no solo a las empresas y otros entes jurídicos, sino también a las personas físicas. Están exentos del pago quienes acrediten insuficiencia de recursos y sean beneficiarios de la justicia gratuita. La ley también tiene en cuenta la puesta en marcha de la Oficina Judicial y las competencias del Secretario Judicial, que es quien debe comprobar si se ha pagado la tasa. Si no se desembolsa la cantidad establecida, no se tramita el pleito.

\section{JUSTICIA Y DISCAPACIDAD EN ESPAÑA}

Según datos estadísticos de la Organización Mundial de la Salud, más de 600 millones de personas en el mundo padecen algún tipo de discapacidad, lo que significa aproximadamente cerca del $10 \%$ de la población mundial. Más de las dos terceras partes de estas personas viven en países en desarrollo, y solo el $2 \%$ de los niños con discapacidad tiene acceso a algún tipo de educación o rehabilitación. En el ámbito europeo, es posible afirmar que 50 millones de personas presentan esta problemática.

En España, un $9 \%$ de la población total padece algún tipo de discapacidad, de los cuales el $58 \%$ son mujeres. Así mismo, la edad es otro de los factores determinantes del fenómeno de la discapacidad. Actualmente en España un 32,2 \% de la población de personas mayores de 64 años sufre algún tipo de capacidad diferente.

Es evidente que el Consejo General del Poder Judicial, como Órgano de Gobierno de la Justicia, no podía permanecer impasible a esta realidad, y de ahí que surja la necesidad de la creación del Foro Justicia y Discapacidad. El mismo nace en diciembre del 2003, con la

46 Fuente del 30/01/2013. www.congreso.es

47 Publicación del (BOE) del 20/11/2012, Madrid, España. 
finalidad básica de coordinar las instituciones jurídicas del Estado para lograr una protección efectiva de los derechos fundamentales de las personas con discapacidad. En particular, el Foro tiene como objetivo favorecer el acceso de las personas discapacitadas a la Justicia en condiciones de igualdad y garantizar su protección jurídica — hacer normal lo que debería ser normal en la sociedad del siglo XXI-.

El Foro Justicia y Discapacidad, creado por el Consejo General del Poder Judicial aprovechando las efemérides del Año de la Discapacidad de las Naciones Unidas, está conformado, además de por el propio Consejo, por el Ministerio de Justicia, el Ministerio de Trabajo, la Fiscalía General del Estado, el Consejo General de la Abogacía Española, el Consejo General de Procuradores de España, el Consejo General del Notariado (Fundación Aequitas), el Colegio de Registradores de la Propiedad Mercantil y de Bienes Muebles de España, y en el año 2008 se incorporó el Consejo General de Colegios Oficiales de Graduados Sociales. A fin de conocer mejor los problemas con los que se enfrentan las personas discapacitadas en su acceso a la justicia, se acordó incorporar al Órgano Rector del Foro algunas de las principales asociaciones representativas, lo que se concretó en el Comité Español de Representantes de Personas con Discapacidad (CERMI) y en la Fundación ONCE. También se han incorporado a lo largo de estos años diversos expertos que han prestado su colaboración en el día a día del Foro Justicia y Discapacidad (diputados del Congreso, magistrados, fiscales...).48

No podemos olvidar que el compromiso primigenio por la tutela de los derechos humanos y del acceso a la justicia para los ciudadanos afectados está en cabeza de los Estados y sus agentes y que corresponde a ellos, en primera instancia, evitar y enfrentar sus violaciones. También es fundamental establecer la importancia de lograr el perfeccionamiento de los sistemas internacionales.

En consecuencia, en principio debe buscarse el perfeccionamiento de los aparatos nacionales de protección, la adaptación de los ordenamientos internos a los estándares internacionales, la creación de recursos idóneos y la expedición de leyes que faciliten el cumplimiento de las obligaciones internacionales.

Además, también depende de los Estados el diseño, la aprobación y la implementación de las reformas necesarias para lograr el fortalecimiento de los sistemas. Debe buscarse, desde los propios Estados, la mejor estrategia para impedir que el esfuerzo concertado por las mejores propuestas se vea frustrado por la ausencia de voluntad política de unos cuantos. Es decir, está en manos de los Estados permitir que los tribunales internacionales se erijan como escenarios idóneos para la garantía del derecho de acceso a la justicia. Son ellos quienes pueden evitar el colapso de los sistemas, dotándolos de recursos suficientes, cumpliendo sus sentencias e incluso evitando que se recura a ellos al adaptar sus ordenamientos internos a

48 www.poderjudicial.es 
los estándares internacionales y al conceder a los particulares los recursos internos suficientes para la salvaguarda de sus derechos.

Ahora bien, cabe resaltar que, a pesar del papel protagónico de los Estados en estas cuestiones, también está en manos de la sociedad civil, la académica y, sobre todo, los propios órganos judiciales nacionales e internacionales, así como también de los órganos políticos internacionales de los que dependen, continuar trabajando en pro de la consolidación de los sistemas internacionales de protección como verdaderas jurisdicciones en cuyo seno los particulares son los protagonistas y cuyo funcionamiento está al servicio de la garantía del derecho de acceso a la justicia.

La consolidación del Derecho internacional de los derechos humanos ha determinado dos avances importantísimos tanto en el ámbito del Derecho internacional público como en la comprensión de los propios sistemas internacionales de protección de los derechos humanos. El primero de ellos es el reconocimiento del individuo como sujeto del Derecho internacional, es decir, la afirmación de los particulares como titulares de derechos, así como de la capacidad jurídica suficiente para reivindicar su protección en el escenario internacional. El segundo, consecuencia del anterior, es la configuración de dichos aparatos internacionales como verdaderas jurisdicciones al servicio de los particulares, más allá de su concepción clásica como instancias creadas por y para los Estados.

Justamente gracias a esta nueva concepción hoy podemos entender mejor el papel de garante que asumen los tribunales internacionales al erigirse como instituciones llamadas a lograr la protección de los derechos humanos a través de la tutela del derecho de acceso a la justicia cuando se tramita una petición individual.

Ahora bien, aun cuando los tribunales internacionales interpretan las normas convencionales tomando como punto de referencia los entes encargados de administrar justicia en el ámbito nacional, no cabe duda de que dicha jurisprudencia es un peldaño más alto en la cadena tejida para asegurar a los individuos el acceso a la justicia.

Así pues, los tribunales internacionales deben cuidar que se satisfagan las siguientes prerrogativas en su propia jurisdicción:

1. El derecho a ser oído, o mejor denominado: el derecho de acción. Es decir, la prerrogativa que tienen todos los individuos, como sujetos de derecho, a presentar su causa ante un Tribunal o ante el ente encargado de administrar justicia.

2. El derecho a un tribunal independiente e imparcial.

3. El derecho a contar con todas las posibilidades de preparar una defensa en igualdad de condiciones. 
4. El derecho a obtener una respuesta en un plazo razonable.

5. El derecho a una repuesta acorde a Derecho, así como el derecho a que se cumpla lo previsto en ella.

En este mismo sentido, podemos decir que al ser el derecho de petición individual una manifestación del derecho que tienen todos los individuos a contar con un recurso efectivo para la protección de los derechos humanos, como parte esencial del derecho de acceso a la justicia (art. $13 \mathrm{CEDH}$ y art. $25 \mathrm{CADH}$ ), dicho mecanismo debe satisfacer las características propias exigidas por las normas de cada sistema.

En consecuencia, debemos tener en cuenta que los sistemas internacionales de protección han de preocuparse no solo por asegurar el acceso a su jurisdicción, en términos formalesreales, sino y sobre todo en proveer justicia, para lo cual es muy importante emitir una sentencia acorde con el Derecho, motivada y ejecutable.

Tampoco podemos dejar de mencionar que la regionalidad, y con ello la real eficacia del sistema interamericano, está en riesgo. En primera instancia, no hay un mecanismo para presionar a los Estados del continente a vincularse al sistema de protección o a permanecer en él. En segundo lugar, aun ratificados los instrumentos básicos del sistema, los Estados pueden abstenerse de aceptar la competencia contenciosa de la Corte. Esta es una de las grandes diferencias de nuestro ordenamiento con el sistema europeo, y no parece existir, por el momento, una solución que permita superar tal obstáculo. Dicha situación genera una afrenta inminente al derecho a la igualdad, pues pareciera ser que los nacionales de los Estados reacios fuesen ciudadanos de segunda clase, en la medida que no cuentan con la misma protección que los nacionales de los Estados miembros del sistema que sí aceptan la competencia de la Corte.

Sin lugar a dudas, el núcleo esencial del derecho de acceso a la justicia es la posibilidad de acceder al aparato de administración de justicia y poder transitar por él para obtener una respuesta real y efectiva.

En otras palabras, entendemos que el acceso a la justicia implica siempre una puerta de entrada al aparato judicial, es decir, poner en marcha la acción, un camino a recorrer, traducido en el proceso, y en este caso, el debido proceso; y una puerta de salida, es decir la sentencia, fundada en Derecho y ejecutable.

Para medir el nivel de garantía de este derecho por parte de los tribunales internacionales es preciso tomar en consideración tanto la posibilidad del acceso directo del individuo a los tribunales como la claridad y la razonabilidad de los requisitos para superar la etapa de admisibilidad de los procesos que se tramitan ante sí. 
Con relación a la primera cuestión, debo decir que en el ordenamiento internacional, la lucha por concederle la titularidad de la acción al individuo, ius standi, no ha sido una batalla fácil, y no en todos los escenarios se ha ganado. Este asunto, que además pasa por la discusión de reconocerle o no al individuo la condición de sujeto del Derecho internacional, es uno de los asuntos diferenciales de los dos sistemas de protección: el europeo y el interamericano. El sistema europeo se ha caracterizado por llevar la vanguardia en este asunto. Desde 1998, dicho aparato se fusionó para dar origen a un tribunal único y permanente, ante el cual los individuos pueden presentar sus causas directamente. Por su parte, en el sistema interamericano solo se ha ganado la primera parte de esta batalla: por el momento, y desde el año 2001, al individuo se le reconoce locus standi, o posibilidad de participación directa en el proceso, pero aún no se le ha concedido la titularidad de la acción ante la Corte. En el escenario europeo, no parece existir mayor tropiezo. Es claro que para presentar la denuncia no se necesita de abogado, puede hacerse por cualquier medio, y una vez ante el Tribunal, los costos del proceso, principalmente los relacionados con los honorarios de los abogados, la producción de las pruebas y el desplazamiento de los interesados hasta el Tribunal, de ser necesario, son asumidos por las partes, que verán dichos gastos retribuidos con el pago de las costas determinadas por el Tribunal, tal como ocurre en todos los procesos judiciales.

Por su parte, en el sistema interamericano, la tramitación del caso suele ser muy costosa. Si bien la denuncia original ante la Comisión no requiere formalmente de abogado, y su presentación no exige mayores formalidades, en la práctica la preparación y presentación de la demanda requieren de conocimientos y recursos que las víctimas no suelen tener. En nuestro sistema parece una verdad a gritos que las víctimas no tienen condiciones para llegar solas ni mucho menos acompañadas a Washington. Además, una vez en trámite ante la Comisión, y luego ante la Corte, es preciso contar con los medios suficientes para pagar un abogado, trasladarse a la sede de los órganos del sistema (Washington, en Estados Unidos, y San José, en Costa Rica) y aportar pruebas.

En consecuencia, debido a la falta de recursos suficientes por parte de los directamente interesados es preciso que organizaciones no gubernamentales (ONG) especializadas asuman la presentación y defensa del caso. Dichas organizaciones, a su vez, deben buscar financiación externa para ejercer estas funciones, pues las costas ordenadas por la Corte suelen no ser suficientes para cubrir todos los gastos en los que se ha incurrido.

Por todo ello, en materia de condiciones previas para el acceso a los sistemas parece evidente que una vez más el contexto financiero y político de cada uno de ellos determina su eficacia. En este escenario, parece que el sistema interamericano tiene algunas lecciones por tomar del europeo. Como se observa, no son pocas las consideraciones que se deben tomar en cuenta para asegurar el acceso al Tribunal. En los sistemas de protección de derechos humanos, especialmente en el americano, a pesar de su loable trabajo, y de los innumerables avances, aún resta mucho por hacer. 


\section{REFERENCIAS}

- Berizonce, Roberto. "El costo del proceso”. J. A., 1995.

- Blaikie, Canon y otros. Vulnerabilidad. El entorno social, politico y económico de los desastres. Colombia: La Red, 1996.

- Cepal. Vulnerabilidad sociodemográfica: viejos y nuevos riesgos para comunidades, hogares y personas. Sintesis y conclusiones. Brasilia, 2002.

- Climent, Ignacio Alonso. "Tercer Mundo, desarrollo, desastres y tecnología. Una mirada desde la geografía”. Serie geográfica N 10. Alcalá de Henares, 2002.

- Gherardi, Natalia. "Notas sobre acceso a la Justicia del Equipo Latinoamericano de Justicia y Género". 2010. En: www.ela.org.ar. Consultado el 29/02/2013. 